\title{
INTERFEJSY INTYMNOŚCI. TENDENCJE INTYMISTYCZNE WE WSPÓŁCZESNYCH GRACH WIDEO
}

PIOTR KuBIŃSKI

\author{
Wydział Polonistyki UW \\ Faculty of Polish Studies, University of Warsaw \\ piotr.kubinski@uw.edu.pl \\ ORCID: 0000-0001-6228-6233
}

\section{WSTĘP}

Niniejszy tekst stanowi próbę zreflektowania tendencji, jaką daje się dostrzec w grach wideo tworzonych w ostatnich latach - tendencja ta polega na nasilonej obecności gier wideo, które prezentują perspektywę intymną i koncentrują się na indywidualnym, jednostkowym doświadczeniu czy przeżyciu bohatera, czyniąc z niego jednocześnie zasadniczy temat gry. Artykuł nie stanowi przeglądu wszystkich gier - ani wszystkich rodzajów gier - wpisujących się w dyskursy intymistyczne, nie usiłuje także przeprowadzić systematyzacji tego zjawiska. Omawiane zjawisko interesuje mnie przede wszystkim w perspektywie interpretacyjnej i genologicznej. Jest ona szczególnie pouczająca, ponieważ gry nie są formą medialną powszechnie identyfikowaną z ekspresją intymnych, formacyjnych czy tożsamościowych doświadczeń. Na analizie tego faktu koncentruję się w pierwszej części artykułu, by przejść następnie do omówienia zjawiska na trzech przykładach. Zostały one wybrane w sposób arbitralny - tak, by dawały możliwie klarowny i szeroki obraz omawianego fenomenu kulturowego.

Stereotypowe wyobrażenie o grach wideo sprawia, że intymistykę oraz gry wideo większość odbiorców byłaby pewnie skłonna lokować w przeciwległych rejestrach kultury. Sądzę, że nawet pobieżna analiza przyczyn tego - zdawałoby się oczywistego - stanu rzeczy pozwoli zarysować istotny kontekst dla niniejszego wywodu. Wspomniana obiegowa opinia - którą można by sprowadzić do twierdzenia, że twórcy gier zwykle koncentrują się na równie widowiskowej, co bezmyślnej i krwawej akcji - znajduje bardzo 
konkretne uzasadnienie: prześledzenie historii gier wideo pokazuje, że spora ich część rzeczywiście koncentrowała się (i nierzadko koncentruje się nadal) raczej na intensywności doznań niż np. na eksploracji wymiaru refleksyjnego czy duchowego. Gry wideo są wszakże w naturalny sposób predysponowane do prezentowania efektownych wydarzeń i do eksponowania sprawczości gracza - wynika to wprost $z$ afordancji tego medium. Gdyby bowiem podjąć próbę definicji gier wideo i ich poetyki, z pewnością dwie cechy objawiłyby się jako jedne $\mathrm{z}$ fundamentalnych. Pierwszą z nich byłaby interaktywność czy też, jak postulował norweski badacz Espen Aarseth, ergodyczność ${ }^{1}$ - a więc ta cecha, która sprawia, że po stronie gracza leży przynajmniej częściowy wpływ na kształt stającego się tekstu kultury i że działania gracza są niezbędne do tego, aby ten tekst w ogóle się ukonstytuował (w myśl zasady, że istotą gry jest to, że jest grana). Można powiedzieć, że w centrum gry stoi zatem działanie gracza. Drugą (i trzecią zarazem) taką cechą fundamentalną poetyki gier wideo jest ich wizualność oraz audialność. Wyodrębniam obydwa aspekty audiowizualności medium osobno dlatego, że wbrew pozorom żaden $\mathrm{z}$ nich nie jest całkowicie niezbędny w grze wideo. Należy wyraźnie zaznaczyć, że - choć wydaje się to paradoksalne - istnieją takie eksperymentalne gry wideo, które są całkowicie pozbawione wymiaru wizualnego $^{2}$. Istnieją też, co pewnie mniej kontrowersyjne, gry zupełnie niekorzystające ze znaków audialnych. Mowa tu jednak o przypadkach marginalnych, niezwykle rzadkich w grach komercyjnych, gdzie audiowizualność stanowi stały punkt decydujący o atrakcyjności danego tytułu.

To właśnie kombinacja wskazanych trzech cech - interaktywności, wizualności, audialności - okazała się istotną dominantą, która determinowała ewolucję gatunków gier wideo. Przyczyniła się m.in. do tego, że jednym $\mathrm{z}$ najbardziej naturalnych kierunków rozwoju gatunków gier było w ostatnich dekadach (a właściwie niemal od początku istnienia medium)

1 E. Aarseth, Cybertekst. Spojrzenia na literaturę ergodyczna, tłum. D. Sikora i in., Kraków-Bydgoszcz 2014.

2 Przykładu dostarcza Spoken Adventures (Spoken Adventures, 2018) - gra, którą można by określić również jako interaktywny audiobook. Zarówno prezentacja wydarzeń, jak i model podejmowania przez gracza interakcji opierają się na interfejsie dźwiękowym i głosowym (rozpoznawaniu mowy), rozgrywce nie towarzyszy wizualny materiał ilustracyjny. 
poszukiwanie sposobów na większe wyeksponowanie i pogłębienie sprawczości gracza, a także zareprezentowanie tej sprawczości w warstwie audiowizualnej w możliwie najbardziej efektowny i wyszukany sposób (także ze względu na rosnące możliwości urządzeń służących do grania) ${ }^{3}$. To m.in. z tych przyczyn tak dużo jest w grach strzelania, pościgów, walki i prób tworzenia coraz to efektowniejszych momentów kulminacyjnych. Za przykład niech posłużą słynne sceny z serii gier wojennych Call of Duty, jak chociażby moment zbombardowania i upadku wieży Eiffla w Call of Duty: Modern Warfare 3 (Infinity Ward, Sledgehammer Games, 2011) czy scena wybuchu bomby jądrowej widzianego $\mathrm{z}$ różnych perspektyw (w tym z perspektywy stacji kosmicznej) w Call of Duty: Modern Warfare 2 (Infinity Ward, 2009). W obydwu sytuacjach mówimy o wykorzystaniu niezwykle wyrazistego symbolu - z jednej strony wieża Eiffla należy do najbardziej emblematycznych znaków reprezentujących kulturę europejską, zniszczenie go można zatem czytać jako swoistą synekdochę, akt ataku na całe dziedzictwo Starego Kontynentu. Z drugiej strony grzyb atomowy jest przerażającym symbolem broni masowego rażenia i znakiem jednego z największych lęków okresu zimnej wojny - dodatkowo widziany z kosmosu wywołuje jeszcze większy efekt uniezwyklenia. W obydwu wypadkach efekt szoku jest więc wywoływany za sprawą ukazania spektakularnego zniszczenia wojennego w trójwymiarowej, dążącej do fotorealizmu estetyce.

W świetle powyższego nie dziwi, że intymistyka jawi się jako ten obszar tekstów kultury, który jest od gier wideo bardzo odległy. Intymistyka, a więc rodzaj piśmiennictwa dokumentu osobistego, którego tradycja na gruncie literatury polskiej zaczęła się kształtować dwa stulecia temu ${ }^{4}$, ma zupełnie

${ }^{3}$ Na marginesie należałoby wskazać, że nie mniej ważnymi przyczynami takiego, a nie innego kierunku rozwoju gier wideo było z jednej strony ich głębokie powiązanie z popkulturą amerykańską, a z drugiej - ich zakorzenienie w przemyśle wojskowym i to, że pierwsze gry wideo powstawały w zimnowojennych ośrodkach naukowych i wojskowych. Na ten temat zob. np. D. Djaouti, J. Alvarez, J.P. Jessel, O. Rampnoux, Origins of Serious Games, [w:] Serious Games and Edutainment Applications, eds. M. Ma, A. Oikonomou, L. Jain, London 2011, zwłaszcza s. 31.

${ }^{4} \mathrm{Na}$ temat początków polskiej intymistyki oraz jej XIX-wiecznych korzeni zob. w szczególności: E. Wichrowska, Twoja śmierć: początki dziennika intymnego w Polsce na przełomie XVIII i XIX wieku, Warszawa 2012, zwłaszcza s. 10-21. 


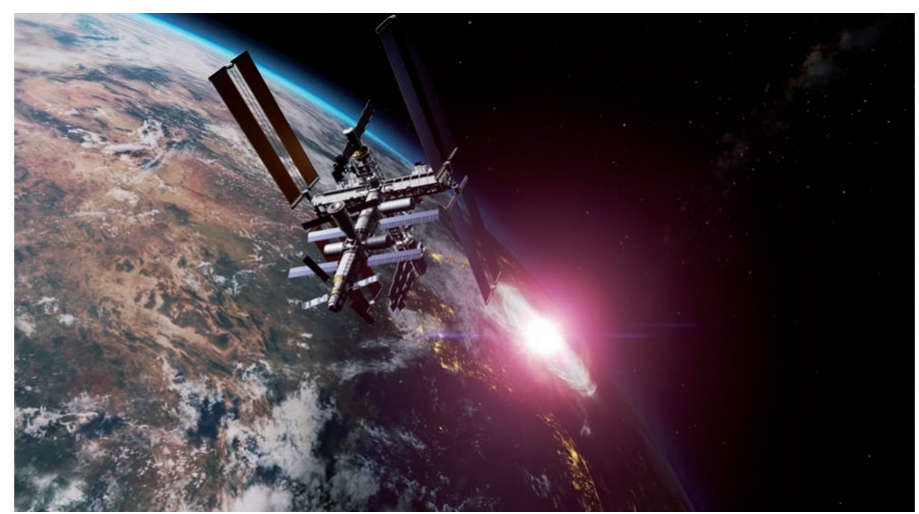

Il. 1. Zrzut ekranu z Call of Duty: Modern Warfare 2 - scena wybuchu bomby jadrowej widziana $z$ kosmosu

inne afordancje niż medium gier. Należą do nich przede wszystkim odsłanianie duchowych, emocjonalnych przeżyć podmiotu, eksponowanie sfery wewnętrznej, często wiążące się z redukcją akcji a eksploracją przemian zachodzących w psychice. Jak zwraca uwagę Konrad Niciński, kategoria intymności może każdorazowo uzyskiwać nieco inny zakres tematyczny oraz inny sposób manifestacji ze względu na wrażliwość i osobowość twórcy, dlatego „pojęcie intymności wymaga każdorazowej negocjacji z utworem literackim, do którego jest stosowane"5. Niezależnie jednak od wynegocjowanego zakresu, gry wideo jawią się jako środowisko wyjątkowo niedogodne do tego, by uprawiać intymistykę, dlatego też to, że taka twórczość w ogóle istnieje $i$, co więcej, nabiera na znaczeniu, jest faktem niezwykle ciekawym i zasługującym na refleksję.

Interesujące mnie tu zjawisko omówię na przykładzie trzech współczesnych gier wideo. Należy przy tym wyraźnie zaznaczyć, że są to bardzo różne gry i każda z nich może posłużyć jako ilustracja wielu innych zjawisk oraz tendencji zachodzących w sferze poetyki współczesnych tekstów kultury cyfrowej. Wątki te będę jednak co najwyżej sygnalizował, o ile oczywiście

${ }^{5}$ K. Niciński, „Drogi Żuczku!...”. O odcieniach intymności w korespondencji Wierzyński-Grydzewski-Lechoń i sposobach ich edytorskiego opracowania, „Sztuka Edycji” 2019, nr 2, s. 97. 
nie przyczyniają się one bezpośrednio do kreowania intymistycznego wymiaru dzieła. Trzy gry, które zostaną poddane analizie, to:

1. Bury me, my Love - wydana w 2017 roku gra francuskiego studia The Pixel Hunt, współtworzona przez ośrodek francuski ARTE France;

2. A Normal Lost Phone - wydana w 2017 roku gra innego francuskiego studia - Accidental Queens, co ciekawe, założonego przez trzy kobiety, co jest rzadkością w tej cały czas zdominowanej przez mężczyzn branży;

3. Wanderlust: Travel Stories - wydana w 2019 roku gra polskiego studia Different Tales ${ }^{6}$, którego współzałożyciel, Artur Ganszyniec, jest autorem manifestu In Praise of Slow Games wyrażającego potrzebę zdrowego, bardziej zrównoważonego procesu produkcji gier oraz potrzebę tworzenia gier bardziej dojrzałych, niespiesznych?

\section{BURY ME, MY LOVE}

Pierwsza z gier, Bury me, my Love, to bardzo wzruszająca opowieść i jednocześnie niezwykle inspirujący przykład tego, jak gry wideo mogą podejmować i twórczo komentować najbardziej aktualne problemy współczesnego świata. W centrum francuskiej produkcji znajduje się zagadnienie trwającej od 2011 roku wojny domowej w Syrii oraz przede wszystkim wynikających z niej syryjskiego kryzysu humanitarnego i wielkiego kryzysu migracyjnego w Europie. Wbrew temu, czego można by się jednak spodziewać, gracz nie wciela się tu w rolę żołnierza, dowódcy wojsk czy osoby w ten czy inny sposób zarządzającej kryzysem. Zamiast tego gra koncentruje się na bardzo indywidualnej i prywatnej historii pewnej syryjskiej rodziny. Główną bohaterką

6 Czuję się zobowiązany zaznaczyć, że jestem w bliskiej relacji z twórcami z Different Tales. Podczas produkcji Wanderlust: Travel Stories miałem okazję testować robocze wersje gry i dzielić się przemyśleniami, natomiast w 2020 r. pełniłem tam funkcję producenta kolejnego produktu: Werewolf: the Apocalypse-Heart of the Forest (Different Tales 2020). Pozwalam sobie jednak zaryzykować tezę, że ta osobista relacja nie wpłynęła ujemnie na rzetelność niniejszego tekstu - dała mi natomiast cenną, wewnętrzną perspektywę, którą staram się tutaj uwzględnić.

7 A. Ganszyniec, In Paradise of Slow Games, Gamasutra, 24.06.2019, https://www. gamasutra.com/blogs/ArturGanszyniec/20190624/345350/In_Praise_of_Slow_Games. php [dostęp 29.03.2021]. 
opowieści jest Nour - kobieta, która próbuje przedostać się z bombardowanej Syrii do Europy. Co ciekawe, gracz śledzi jej losy z perspektywy męża imieniem Majd, który został w domu, w mieście Homs, i który opiekuje się rodziną pozostałą na miejscu. Niebezpieczna przeprawa do Europy jest relacjonowana za pośrednictwem komunikatora internetowego, którym rozłączone małżeństwo stale się posługuje - tak jak rzeczywiście czynią to tysiące rozłączonych uchodźczych rodzin.

Warto podkreślić perspektywę ustawioną w szczególny sposób. Gracz wciela się tu nie w bohaterkę, która przeżywa dramatyczne chwile w czasie migracji, tylko w jej męża, który poznaje losy kobiety w pozycji nieomal całkowicie biernej. Jedyne, co może robić, to śledzić korespondencję Nour i Majda (która często przybiera bardzo intymną formę) i na różne sposoby odpisywać na wiadomości małżonki - zostaje niemal całkowicie pozbawiony sprawczości, a jego rola sprowadza się do roli obserwatora czy też komentatora ${ }^{8}$.

Nastrój, emocjonalność i tematykę gry doskonale ilustruje jej tytuł. Bury me, my Love oznacza w wolnym tłumaczeniu „Pochowaj mnie, moja miłości”. Jak tłumaczą sami autorzy, te słowa są przekładem syryjskiego pożegnania i jednocześnie wyrazu miłości, oznaczają po prostu - „uważaj na siebie i nawet nie próbuj umrzeć przede mną" . Gra eksploruje tematy związane z intymnością i relacją z najbliższymi, którzy - przez to, że używają komunikatorów - są cały czas obecni, dostępni - choć oczywiście nie towarzyszą fizycznie przemieszczającej się osobie. Może to rodzić konkretne rozterki dla obydwu stron komunikacji. Z perspektywy osoby podróżującej: czy na pewno informować bliskich o wszystkim, co się dzieje? A może przemilczać część wydarzeń, żeby ich nie martwić? Z perspektywy osoby pozostającej

8 Ta bierna rola zostaje dodatkowo podkreślona przez to, że gracz nie może inicjować konwersacji w dowolnym momencie, może tylko odpowiadać na wiadomości wtedy, gdy Nour jest dostępna na czacie. Domyślne ustawienia gry sprawiają, że gracz często musi czekać na nową wiadomość od bohaterki (gracz może wówczas wyjść z gry i wrócić do niej, gdy pojawi się nowa wiadomość). Ta osobliwa sytuacja temporalna zasługuje na osobną analizę, na ten temat zob. np. D. Jayemanne, Chronotypology: A Comparative Method for Analyzing Game Time, „Games and Culture” 2020, No. 7.

9 Opis gry na stronie sklepu Google Play: https://play.google.com/store/apps/ details?id=com.plug_in_digital.emma\&hl=en_US\&gl=US [dostęp 30.03.2021]. 
na miejscu: czy dzielić się swoim niepokojem? Czy druga strona nie pomija czegoś istotnego w swojej relacji z podróży? Co ciekawe, ponieważ wcielamy się nie w Nour, tylko w jej męża, Majda, nie możemy decydować o tym, kiedy bohaterka podzieli się z nami swoimi przeżyciami, czy opowie nam całą prawdę ani w jakiej formie to zrobi. Co prawda, jej komunikaty i reakcje będą różne w zależności od tego, jak Majd (gracz) prowadził wcześniej konwersację - czy czuje w nim wsparcie, czy mimo dystansu geograficznego czuje jego bliskość - a zatem można powiedzieć, że gracz ma pewien wpływ na przebieg zdarzeń, jednak wpływ ten jest jedynie pośredni, nie polega na możliwości bezpośredniego decydowania o tym, co wydarzy się później. Co więcej, często wybory podejmowane przez gracza przynoszą konsekwencje odwrotne do pierwotnie zakładanych intencji.

Widzimy więc, że jednym z tematów gry jest to, w jaki sposób migranci używają komunikatorów internetowych, takich jak Whatsapp czy Messenger. Współczesna medialność i jej interfejsy stają się narzędziem do mówienia o bardzo intymnej sferze życia. Co ważne, twórcy nie sięgali tu jedynie do swojej fantazji i do wyobrażeń o tym, jak uchodźcy komunikują się z bliskimi. Gra powstała na podstawie relacji wielu uchodźców, z którymi rozmawiali twórcy - szczególne znaczenie miała tu opowieść Dany, kobiety, która pełniła funkcję konsultantki redakcyjnej i która sama wcześniej przeżyła podobną co Nour historię - a raczej jedną z kilkunastu wersji tej historii, jakie można poznać $\mathrm{w}$ grze ${ }^{10}$. To dążenie do realizmu,

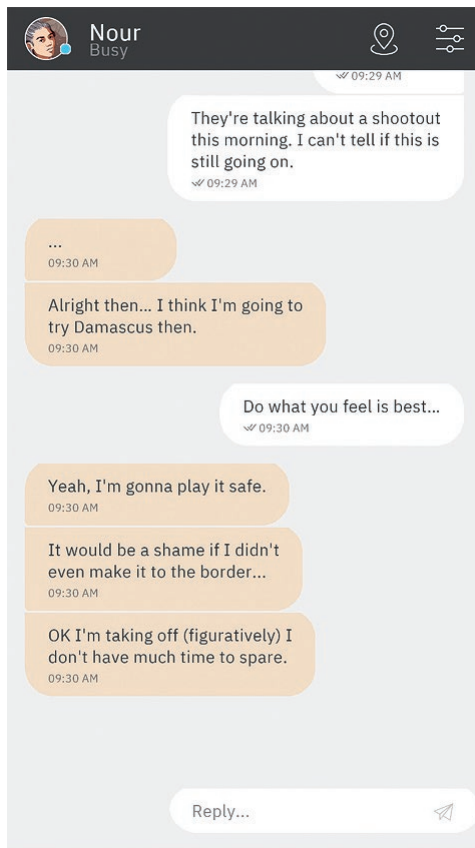

Il. 2. Zrzut ekranu z gry Bury me, my Love uruchomionej na smartfonie

10 Zob. np. R. McMillan, D. Jayemanne, I. Donald, Reality inspired games: expanding the lens of games' claims to authenticity, [w:] DiGRA '20 - Proceedings of the 2020 DiGRA International Conference: Play Everywhere, b.m.w. 2020, s. 3. 
chęć stworzenia ekwiwalentu rzeczywistej komunikacji prowadzonej przez uchodźców, sprawia, że Bury me, my Love zbliża się do nurtu newsgames, a więc do gier publicystycznych czy reporterskich, których twórcy wykorzystują medium gry jako narzędzie dziennikarskiego opisu rzeczywistości ${ }^{11}$. Wyjątkowość gry francuskiego Pixel Hunt - nawet na tle tego nietypowego gatunku gier zaangażowanych - polega jednak na przedstawieniu problemu przez pryzmat losów konkretnych osób, których dramaty oglądamy z tak bliskiej perspektywy, jak to tylko możliwe.

Do maksymalnego przybliżenia i pogłębienia tej perspektywy Bury me, my Love w szczególny sposób wykorzystuje swoją medialność. Warto bowiem zauważyć, że rozgrywka w całości prezentowana jest jako czat prowadzony za pośrednictwem fikcyjnego komunikatora przypominającego rzeczywiste aplikacje smartfonowe ${ }^{12}$. Pierwotnie gra była opublikowana właśnie na urządzeniach przenośnych (wydanie na komputery osobiste pojawiło się później) i to właśnie na nich najbardziej widoczny jest precyzyjnie zaprojektowany efekt remediacji. Gra imituje bowiem aplikację nie tylko w warstwie interfejsu czy w sposobie prezentacji treści, upodabnia się do niej także na poziomie sposobu funkcjonowania w systemie operacyjnym telefonu: kiedy użytkownik wyjdzie $\mathrm{z}$ aplikacji, na smartfonie będą pojawiać się powiadomienia o nowych wiadomościach od Nour - tak jakby gra rzeczywiście była komunikatorem. Konsekwencją dla osoby korzystającej z gry na smartfonie jest to, że rozgrywka przestaje być wyraźnie oddzielona od korzystania z pozostałych aplikacji w urządzeniu - wyjście z gry nie kończy jej, tylko zmienia jej tryb, gra staje się inherentną częścią doświadczenia użytkowania smartfonu. Jest to $\mathrm{z}$ całą pewnością temat zasługujący

${ }^{11} \mathrm{Na}$ temat newsgames zob. zwłaszcza: I. Bogost, S. Ferrari, B. Schweizer, Newsgames: Journalism at Play, Cambridge, MA-London 2012. Tekst dostępny online: http://www.digra.org/wp-content/uploads/digital-library/DiGRA_2020_paper_440. pdf; [dostęp 30.03.2021].

${ }_{12}$ Choć ma to mniejsze znaczenie w całości rozgrywki, należy odnotować, że gra remediuje również aplikację wyświetlającą mapę świata - w ten sposób wyświetla informację o aktualnym miejscu pobytu bohaterki. W interesujący sposób podjęła to zagadnienie Agata Waszkiewicz w wystąpieniu Problem czwartej ściany w niezależnych grach interfejsowych podczas konferencji Interfejsy: granice systemów $i$ światów (5.03.2021 r., Uniwersytet Warszawski). 
na szersze omówienie, tu jednak ograniczę się jedynie do zasygnalizowania, w jaki sposób wpływa to na kształtowanie intymistycznego wymiaru gry: za sprawą uwiarygodnienia przekazu, zanurzenia go w medialności smartfonu, gracz może łatwiej ulec iluzji bezpośredniego dostępu do prywatnej korespondencji bohaterów i łatwiej poczuć, że jest uczestnikiem prezentowanych wydarzeń.

Historia Nour może się zakończyć na dziewiętnaście sposobów - w każdym wypadku gracz może wówczas usłyszeć wiadomość głosowa, którą bohaterka wysyła do męża. Niektóre z historii kończą się jednak śmiercią bohaterki. W jednej $\mathrm{z}$ takich scen udostępniane nagranie jest $\mathrm{w}$ istocie dramatycznym wyznaniem miłości - z jednej strony wypełnionym strachem wobec tego, co nieuniknione, z drugiej strony pełne szczerej żarliwości, które z poruszającą dramaturgią zostają oddane przez aktorkę użyczającą głosu postaci Nour:

Majd... I don't know if you get to listen to this... I'm freaking out... If the rescuers won't come soon, we won't... we won't... hold on. We need help! I wanted to tell you: I love you... I love you, I love you, I love you, I love you! Ah, shit...! I love you! I love you, I love you, I love you, I love you, I love you, I love you, I love you...

Intymny wymiar powyższego komunikatu zakończonego urywanym płaczem wynika przede wszystkim z tego, że wyznanie miłosne, które samo w sobie ma przecież bardzo prywatny status, jest dodatkowo wypowiadane w sytuacji granicznej, której skrajne i bardzo głębokie emocje również nie mają przecież charakteru publicznego. 


\section{A NORMAL LOST PHONE}

Następną grą, której chciałbym poświęcić uwagę, jest A Normal Lost Phone. Tym, co łączy ją z Bury me, my Love, jest z całą pewnością oparcie rozgrywki na remediowaniu interfejsu smartfonu. W A Normal Lost Phone remediacja ta jednak nie ogranicza się do konkretnej aplikacji, ale do całego systemu obsługi takiego urządzenia. W grze przyjmujemy bowiem perspektywę osoby, która znalazła czyjś smartfon i stara się ustalić jego właściciela, by zwrócić znaleziony przedmiot. W tym celu gracz przeszukuje wiadomości, zdjęcia, wpisy w portalach społecznościowych - słowem całą zawartość urządzenia.

Odkrywanie tych treści układa się w precyzyjnie zaplanowaną przez twórców sekwencję kroków. Przykładowo: aby móc korzystać z części aplikacji, niezbędne jest nawiązanie przez smartfon połączenia się z internetem - gracz może to zrobić za pomocą miejskiej sieci Wi-Fi. W tym celu trzeba jednak najpierw ustalić, jakie jest hasło do tej sieci. Dzięki lekturze wiadomości SMS-owych zapisanych w telefonie gracz może dowiedzieć się, że hasłem tym jest kod pocztowy miejscowości Melren, w którym toczy się akcja. Naturalnym zadaniem staje się więc ustalenie, jaki jest ów kod pocztowy - tę informację można natomiast znaleźć w aplikacji pogodowej (prognoza jest podawana dla danej miejscowości, której nazwie towarzyszy właśnie kod pocztowy). A Normal Lost Phone jest więc sekwencją łamigłówek - aby je rozwiązać, trzeba łączyć fakty, którymi aktualnie dysponuje gracz. Informacje gromadzone w ten sposób przez gracza składają się na obraz osoby, która boryka się z głębokimi problemami z własną tożsamością seksualną i - jak okazuje się w toku rozgrywki - ostatecznie podjęła trudną decyzję o korekcie płci.

Co ciekawe, podobieństwo obydwu omawianych dotychczas gier polega na tym, że nie ustawiają one gracza w centrum wydarzeń i że nie ma on na te wydarzenia wielkiego (a w A Normal Lost Phone - żadnego) wpływu. Istotna różnica polega natomiast na tym, że w Bury me, my Love akcja rozwija się na oczach gracza, tymczasem w A Normal Lost Phone gracz jedynie rekonstruuje obraz wydarzeń już minionych; jest więc już nawet nie obserwatorem, ile archeologiem.

Skomentowania wymaga, rzecz jasna, to, że wszystkie informacje o głównej postaci dramatu gracz pozyskuje z perspektywy podglądacza. Aby rozwiązać kolejne zagadki, trzeba bowiem wejść w posiadanie bardzo intymnych danych, które nie były przeznaczone dla niczyich oczu poza oczami 


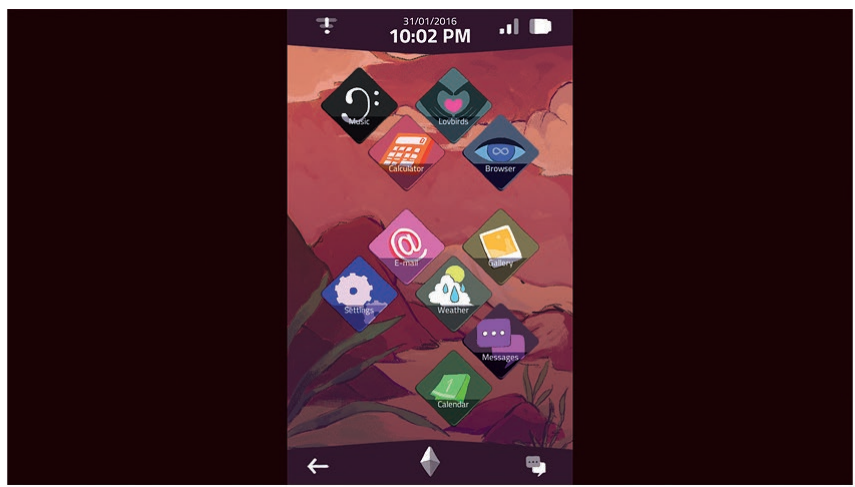

Il. 4. Zrzut ekranu z gry A Normal Lost Phone (w wersji PC) - widok głównego ekranu smartfonu, po którym gracz nawiguje w grze

właściciela. Najdobitniejszym tego przykładem jest sekwencja, w której gracz musi złamać hasło do konta na jednym $\mathrm{z}$ forów internetowych - to, że „łamanie tych zabezpieczeń jest powszechnie uważane za nieetyczne”, nie wymaga dodatkowego uzasadnienia. Oczywiście sytuacja narracyjna w grze jest ukształtowana w taki sposób, by dostarczać usprawiedliwienia tym działaniom: podmiot kierowany przez gracza postępuje w dobrej wierze, chce wszakże zwrócić telefon właścicielowi. Nie zmienia to faktu, że działanie gracza ma bardzo wyraźnie charakter podglądactwa czy wręcz voyeryzmu - a na pewno brutalnego wchodzenia w obszar cudzej intymności. Jest to tym bardziej odczuwalne, że treść materiałów (wiadomości, zdjęć, wpisów w portalach społecznościowych etc.) dostępnych z poziomu wirtualnego smartfona częstokroć odnosi się do kwestii bardzo prywatnych, takich jak: relacje towarzyskie, preferencje seksualne czy wreszcie proces dochodzenia przez główną postać dramatu do decyzji o korekcie płci. Twórcy A Normal Lost Phone nie zdecydowali się na pójście w kierunku taniej sensacji - zamiast tego dali graczowi dostęp do intymnych treści i pozwolili zagłębić się w historię osoby przeżywającej prywatny dramat. Wydaje się bowiem bezsporne, że funkcją tego podglądactwa jest nie tyle

13 P. Chłopek, Intymistyka 2.0. Wpływ postępującej dygitalizacji na badania nad współczesna prywatnością, „Sztuka Edycji” 2019, nr 2, s. 180. 
(a przynajmniej: nie przede wszystkim ${ }^{14}$ ) wywoływanie dreszczu emocji, ile właśnie umożliwienie graczowi, by przyjrzał się wspomnianemu procesowi dochodzenia do decyzji o korekcie płci. Nadrzędnym celem gry zdaje się w tej sytuacji przedstawienie pogłębionego obrazu osób transseksualnych oraz opowiedzenie w zniuansowany sposób o rozterkach i problemach, które nierzadko stają się udziałem tej grupy.

Daje się tu dostrzec ciekawy zabieg narracyjny, który ma silnie perswazyjne działanie. Aby wzmocnić oddziaływanie przekazu, autorzy zdecydowali się przedstawić historię nie tyle za pośrednictwem narratora (którego pośrednictwo mogłoby wywoływać wrażenie stronniczości czy wprowadzania określonej aksjologii), ile poprzez danie graczowi bezpośredniego wglądu w intymne treści. Daje to wrażenie niezakłamanego dostępu do wrażliwości osoby - w tym wypadku transpłciowej. W rezultacie gracz może mieć wrażenie, że zapis emocji i doświadczeń jest bardziej autentyczny, a więc też wiarygodny.

Zarówno A Normal Lost Phone, jak i Bury me, my Love opowiadają historię poprzez interfejsy dające dostęp do najbardziej prywatnych i intymnych treści, jakie - w mniejszym lub większym stopniu - wytwarza każdy uczestnik kultury korzystający z sieci. Analiza obydwu gier pozwala zatem postawić tezę tyleż wyraźną, co trudną do zanegowania: w kult u rze współczesnej intymistyka przesunęła się bardzo wyraźnie w stronę cyfrowości, a jej podstawowym nośnikiem stały się smartfony. Wiadomości SMS-owe, historie połączeń, wiadomości z poczty internetowej, prywatne wiadomości w serwisach społecznościowych, historia interakcji w tych serwisach, dane $\mathrm{z}$ aplikacji randkowych, prywatne zdjęcia oraz filmy wideo, notatki, historia wszystkich transakcji finansowych widoczna z poziomu aplikacji bankowej, a nawet historia naszej dokładnej lokalizacji, a więc gdzie, kiedy i jak długo byliśmy w danym czasie... - wszystkie tego typu dane są przecież agregowane w urządzeniu, które

14 Ten właśnie aspekt - oraz szerzej: intymistyczny wymiar gry - jest wyróżniony w oficjalnym opisie w kanałach cyfrowej dystrybucji. Pierwsze zdanie tego opisu - a więc swoisty slogan gry - głosi: „A Normal Lost Phone is a game about exploring the intimacy of an unknown person whose phone was found by the player" [wyróżnienie - P.K.]. Zob. https://play.google.com/store/apps/details?id=com. accidentalqueens.anormallostphone\&hl=pl\&gl=US [dostęp 30.03.2021]. 


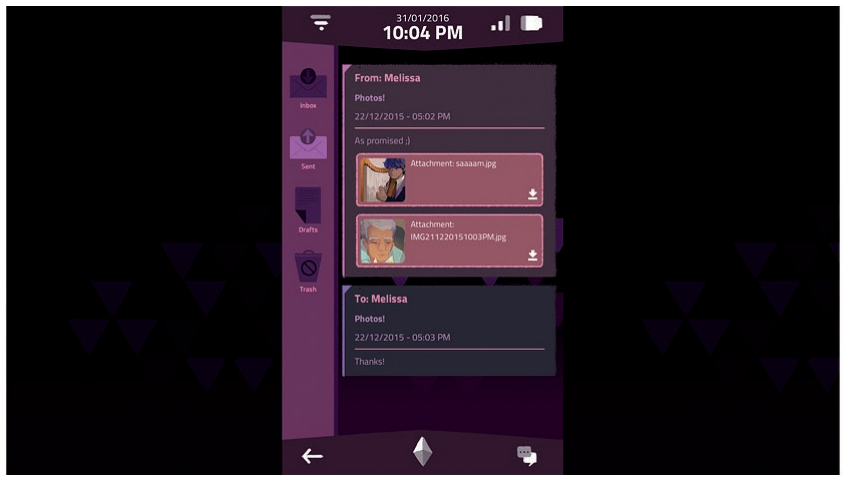

Il. 5. Zrzut ekranu z gry A Normal Lost Phone (w wersji PC) - widok aplikacji mailowej; przeglądanie treści korespondencji (oraz innych materiałów zebranych na urządzeniu) z jednej strony narusza prywatność właściciela, z drugiej-jest niezbędne do poczynienia postępu $w$ rozgrywce

większość konsumentów współczesnej kultury nosi ze sobą stale w kieszeni czy torebce. Sądzę, że należy tu wręcz mówić o swoistej in ty m i st yce $2.0^{15}$, ponieważ wspomniane ślady cyfrowe odnotowywane na urządzeniach cyfrowych i w sieci tworzą de facto współczesne dzienniki intymne - z tym że częstokroć pisane bez świadomości ich autorów, niejako mimochodem. O tym, jak bardzo intymne są te materiały, najlepiej niech świadczy niepokój, z jakim większość z użytkowników smartfonów musiałaby się zmierzyć, gdyby to prywatne urządzenie trafiło w niepowołane ręce niezablokowane, niezabezpieczone hasłem.

\section{WANDERLUST: TRAVEL STORIES}

Trzecia gra, która posłuży mi jako ilustracja tendencji intymistycznych we współczesnych grach wideo, istotnie różni się od dwóch omówionych wcześniej. Przede wszystkim Wanderlust: Travel Stories nie posługuje się remediacją smartfona. Gra, której tytuł można by przetłumaczyć jako „Zamiłowanie do wędrowania: historie podróżnicze”, to przygodowa produkcja realizująca

15 Posługuję się tu - choć w nieco innym znaczeniu - określeniem, które wcześniej zaproponował w cytowanym już tekście Patryk Chłopek. Autor nie definiuje tam jednak tej kategorii, a odnosi ją jedynie do pracy edytorskiej „nad zdygitalizowanymi tekstami intymistycznymi”. Zob. P. Chłopek, op. cit., s. 180. 
się przede wszystkim w wymiarze tekstowym. Główną aktywnością gracza jest czytanie tekstu, który zwykle zajmuje większą część ekranu (bywa, że zamiast tekstu ekran pokazuje głównie mapę przedstawiającą trasę pokonywaną przez bohatera danej opowieści). Gracz poznaje kolejne akapity historii wraz z ilustrującymi je fotografiami i na tej podstawie dokonuje wyborów fabularnych, które z jednej strony mogą mieć wpływ na dalszy przebieg gry, z drugiej - wpływają też czasem na trzy podstawowe parametry charakteryzujące stan bohatera. Są to: poziom stresu, poziom zmęczenia oraz zasobność portfela. Aktualne wartości tych trzech wskaźników będą często zmieniać brzmienie poszczególnych akapitów wypowiadanych przez narratora.

Wanderlust: Travel Stories to gra ze szkatułkową konstrukcją fabularną. Rama tej historii mówi o spotkaniu kilkorga nieznajomych podróżników na Wyspie Wielkanocnej. Wędrowcy zaczynają opowiadać sobie historie swoich podróży - każda z nich jest osobnym rozdziałem, który gracz może rozegrać na wiele sposobów. Co istotne, każda z tych opowieści przedstawia ważne, często tożsamościowo definiujące przeżycia bohaterów. Nie znaczy to, że te historie są zawsze spektakularne czy widowiskowe - wręcz przeciwnie. Czasem tworzone w kilkugodzinnej opowieści napięcie nie zostaje ostatecznie skanalizowane przez zbudowanie mocnego punktu kulminacyjnego. Bywa, że pozostawiają one użytkownika z poczuciem nienasycenia czy swoistego zawodu wynikającego z braku puenty czy mocnego finału. Autorzy gry robią to jednak z premedytacją - nie trzymają się kurczowo popularnych wśród twórców gier wideo prawideł tworzenia dobrych historii opartych na Campbellowskim monomicie i jego opracowaniach ${ }^{16}$. Zamiast tego zdają się sugerować, że tak opowieść, jak podróż nie muszą mieć zawsze dramatycznego przebiegu, by można było je uznać za wartościowe, ważne czy po prostu ciekawe.

Intymistyczny wymiar opowieści w Wanderlust: Travel Stories realizuje się w nieco inny sposób niż w pozostałych analizowanych grach. Uwidacznia się to w formie prowadzenia opowieści przez poszczególnych narratorów,

16 Do popularnych w branży gier wideo opracowań Campbellowskiej koncepcji podróży bohatera należy m.in. Ch. Vogler, Podróż autora. Struktury mityczne dla scenarzystów i pisarzy, tłum. K. Kosińska, Warszawa 2010. Zob. też: J. Campbell, Bohater o tysiącu twarzy, tłum. A. Jankowski, Kraków 2013. 


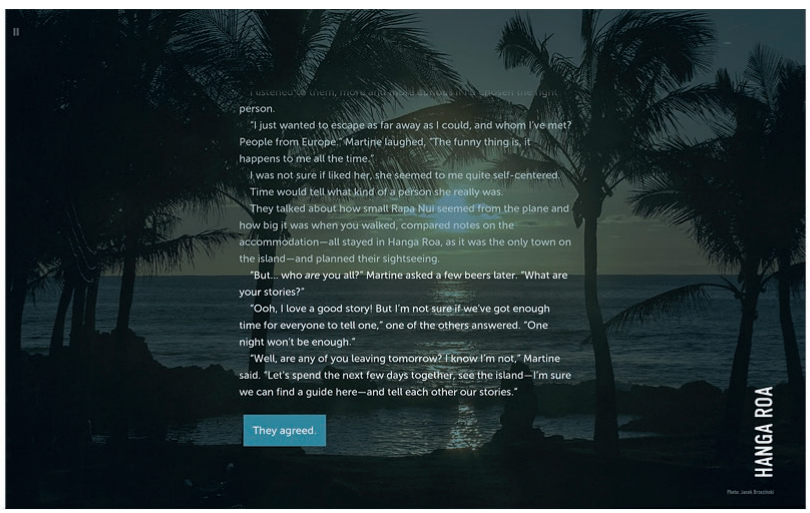

Il. 6. Zrzut ekranu z gry Wanderlust: Travel Stories prezentujacy ramę narracyjna opowieści - spotkanie podróżników na Wyspie Wielkanocnej

których wypowiedzi wpisują się w poetykę wspomnienia lub dziennika $\mathrm{z}$ podróży. Taka formuła pozwala $\mathrm{z}$ jednej strony na literacki opis nowo poznawanych miejsc, ale $z$ drugiej - także na refleksyjne wejrzenie we własne wnętrze i przyjrzenie się swoim motywacjom, emocjom i pragnieniom. Interesującego przykładu dostarcza historia Martine, studentki mody, która w rozdziale The Essential Gap Year opowiada historię swojego rocznego wyjazdu do Tajlandii. Na początku tego rozdziału bohaterka napotyka innego turystę, Maksa z Nowego Jorku - jeśli zdecyduje się z nim porozmawiać, to usłyszy od niego ważne pytanie: „Dlaczego tu jesteś?”. Co ciekawe, to gracz musi podjąć decyzję o motywacji bohaterki, ma przy tym do wyboru trzy odpowiedzi: „Mam dość Zachodu”, „Muszę odnaleźć siebie” i „Pragnę czegoś autentycznego". Charakterystyczne, że każda z dostępnych odpowiedzi - nawet jeśli odnosi się do świata zewnętrznego, np. do rodzinnych stron bohaterki - faktycznie świadczy o pewnej potrzebie wewnętrznej. Decyzja co do motywacji bohaterki ma istotne skutki dla późniejszej rozgrywki, ponieważ od wskazanej przez gracza (a więc faktycznej) motywacji bohaterki będzie zależeć przebieg wielu scen oraz treść przemyśleń, które wypełniają te sceny.

Aby ukończyć rozdział, gracz musi oczywiście wraz z bohaterką przenosić się z miejsca na miejsce, jednak można zaryzykować tezę, że w tej grze o podróżowaniu to nie podróże są najważniejsze. Istotniejsze zdają się pytania: 


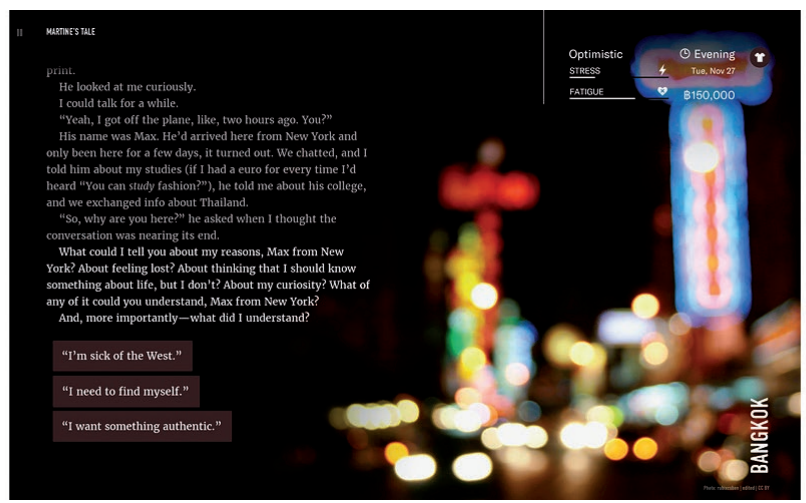

Il. 7. Zrzut ekranu z gry Wanderlust: Travel Stories prezentujący fragment rozdziału The Essential Gap Year - moment, $w$ którym gracz musi zadecydować o wewnętrznej motywacji bohaterki

dlaczego w ogóle podróżujemy? Co podróże robią z człowiekiem? Co w ich trakcie odkrywamy? Jak reagujemy na nowo poznawane miejsca i dlaczego nasze reakcje są właśnie takie? Odpowiedzi na te pytania rzadko padają w grze wprost, zwykle raczej wyłaniają się w akcie interpretacji wyborów gracza i dzięki bliskiemu, tekstowemu wglądowi w psychikę bohaterów.

O intymistycznym wymiarze Wanderlust: Travel Stories decyduje jednak nie tylko to, że gra koncentruje się na kwestiach wewnętrznych motywacji i często głęboko skrywanych potrzeb - bywa, że decyduje o tym także akcja prezentowana w poszczególnych rozdziałach. Widać to wyraźnie na przykładzie rozdziału Today is Always Gone Tomorrow opowiadającego historię bohaterki imieniem Adília, byłej reporterki wojennej, która po latach powróciła do ukochanej Afryki nieodmiennie targanej konfliktami wojennymi. Profesja bohaterki może sugerować, że rozdział będzie obfitować w momenty pełne niebezpieczeństw, być może nawet w sceny wojenne jest jednak zupełnie odwrotnie. Rozdział zaczyna się od zaskakującej komendy: „Look at the coffin” („Spójrz na trumnę”). Ten bardzo mocny gest otwierający historię musi pozostawić gracza w pierwszej chwili w pewnej dezorientacji, ponieważ nie wiadomo, czego spodziewać się dalej.

Dopiero kliknięcie napisu, będące reprezentacją faktycznego gestu spojrzenia na trumnę, ujawnia, że w rzeczywistości akcja toczy się na pogrzebie. Przez pierwsze minuty rozgrywki narratorka wspomina zmarłą przyjaciółkę 


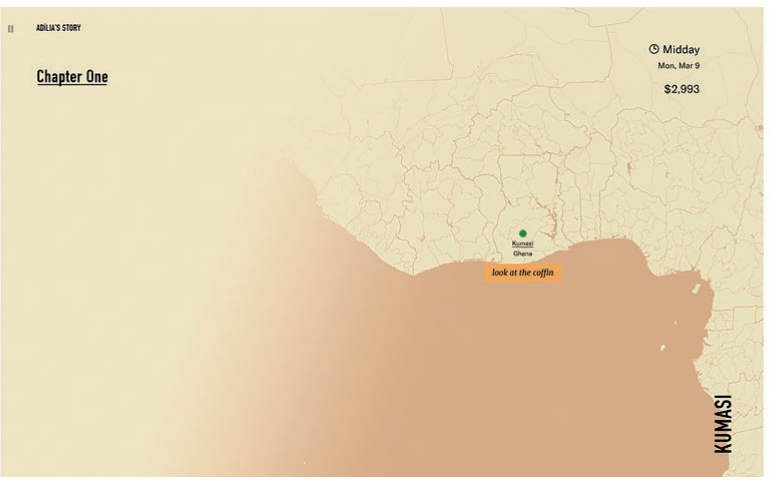

Il. 8. Zrzut ekranu z gry Wanderlust: Travel Stories prezentujacy początek rozdziału Today is Always Gone Tomorrow

imieniem Adwoa („Everything here reminded me of Adwoa”), a zasadnicza treść rozdziału polega na odgrywaniu przez gracza wspomnienia o zmarłej, różnych przeżywanych wspólnie chwil i przeprowadzonych rozmów. Wspominanie zmarłej osoby, a szczególnie zmarłej przyjaciółki, które jest istotnym tematem rozdziału, ma niewątpliwie charakter intymny, tym bardziej że bohaterka nie wspomina na głos, a snuje refleksję w myślach.

Omawiany tytuł ponad wszelką wątpliwość wpisuje się w nurt intymistyczny z jeszcze jednego powodu. Jak nieomal każda gra, tak i Wanderlust: Travel Stories jest dziełem nie pojedynczego autora, ale zespołu twórców, których wrażliwość, doświadczenia i indywidualna perspektywa w różnym stopniu dochodzą do głosu w finalnej wersji utworu. W wypadku dzieła Different Tales ta bachtinowska wielogłosowość pozwoliła jednak - co rzadkie - opowiedzieć także historie bardzo osobiste, prywatne, odwołujące się do rzeczywistego doświadczenia autorów. Jak wspomniałem, opowieść, która stanowi ramę dla całej struktury narracyjnej gry, toczy się na Wyspie Wielkanocnej - to tu spotykają się podróżnicy, których historie gracz przeżywa w kolejnych rozdziałach. Ta wymiana historii wędrowców na końcu świata jest interpretacją konkretnego wydarzenia z życia Jacka Brzezińskiego, jednego z dwóch głównych twórców Wanderlust: Travel Stories i zarazem współzałożycieli studia. Jak Brzeziński opowiedział mi $\mathrm{w}$ indywidualnej rozmowie, rzeczywiście spotkanie innych podróżników 
na Wyspie Wielkanocnej - oraz cała pięciomiesięczna podróż, której to spotkanie stanowiło część - było dla niego wydarzeniem tożsamościowo formacyjnym, życiowym punktem zwrotnym. Na potrzeby niniejszego artykułu przeprowadziłem z Brzezińskim rozmowę, aby ustalić, na ile to prywatne doświadczenie znajduje według autora odzwierciedlenie w grze ${ }^{17}$. Jak sam tłumaczy:

To był faktycznie moment przełomowy: był 2010 rok, miałem wtedy okres rocznego wypowiedzenia z CD Projektu, gdzie wcześniej pracowałem - ze względu na podpisane $\mathrm{NDA}^{18}$ nie mogłem przez ten rok pracować w żadnym innym miejscu. A jednocześnie od zawsze bardzo chciałem podróżować. Więc skorzystałem z okazji i po prostu zacząłem to robić; wyjechałem od razu na pięć miesięcy.

Współautor Wanderlust: Travel Stories opowiada przy tym, że Wyspa Wielkanocna była dla niego tyleż wymarzonym, co niedosiężnym celem podróży:

Zawsze mi się wydawało, że Wyspa Wielkanocna to takie mistyczne miejsce, które wspaniale byłoby odwiedzić - ale jednocześnie przez większość życia nie wyobrażałem sobie, że w ogóle można tak daleko dotrzeć, do takiego miejsca pośrodku wielkiej wody. Tymczasem ta moja wyprawa w 2010 roku całkowicie to zmieniła. Był to mój pierwszy tak długi wyjazd, wybrałem się wtedy w podróż dookoła świata - i nagle w tej perspektywie Wyspa Wielkanocna stała się całkiem realnym punktem wędrówki, bo jest dokładnie w połowie drogi pomiędzy innymi odległymi miejscami ${ }^{19}$.

${ }_{17}$ Poniższe cytaty pochodzą z autoryzowanej rozmowy telefonicznej z Jackiem Brzezińskim przeprowadzonej 30.03.2021 r.

18 NDA (z ang. Non-Disclosure Agreement), czyli charakterystyczna m.in. dla branży gier wideo umowa o zachowaniu poufności, której warunkiem bywa to, że pracownik przez ustalony okres (np. jednego roku) nie może podejmować zatrudnienia w firmie prowadzącej działalność konkurencyjną.

${ }_{19}$ Co charakterystyczne, nawet spontaniczny sposób opowiadania przez Brzezińskiego o Wyspie Wielkanocnej jest zbliżony do tego, który został zawarty w grze. Pierwsze słowa opisu tego odległego lądu brzmią: „A small green dot... in the middle of Pacific... 6 hours flight to anywhere" (Different Tales, 2019). 
Brzeziński wyjaśnia także, że figura spotkania podróżników na końcu świata odpowiada temu, co faktycznie wydarzyło się na Wyspie Wielkanocnej i co było dla niego osobiście bardzo istotnym przeżyciem:

To był pierwszy raz, kiedy byłem na takim spotkaniu couchsurferów - było tam z siedem osób, w większości byli to turyści, którzy mieli ciekawe historie do opowiedzenia, czy to o podróżach, czy to po prostu o życiu. To było dla mnie niezwykle ważne doświadczenie, ponieważ był to jednocześnie moment, kiedy przyglądałem się temu, jak się żyje w różnych miejscach na świecie. Pamiętam, że na tym spotkaniu była np. dziewczyna z Niemiec, która zrobiła sobie akurat rok przerwy od obowiązków i po prostu jeździła po świecie. A dla mnie do tej pory to było coś niewyobrażalnego, żeby np. zrobić rok przerwy w studiach albo skoczyć do Nowej Zelandii i tam, dajmy na to, pracować w hostelu i po prostu przez jakiś czas żyć sobie w jakimś ciekawym, odległym miejscu. To doświadczenie - patrząc z perspektywy czasu - było momentem przełomowym; później starałem się podróżować dużo więcej.

Brzeziński rzeczywiście od tego czasu stale szuka okazji do nowych podróży, czasami wyjeżdża np. na kilka dni w odległe strony, jednak nie tyle na wakacje, ile by po prostu pomieszkać czy też pożyć w innym miejscu. Dość powiedzieć, że gdy przeprowadzałem z nim tę rozmowę, Brzeziński był akurat na kanaryjskiej wyspie La Palma, gdzie pracował nad następną grą.

W ten sposób uwidacznia się jeszcze jeden przejaw tendencji intymistycznych we współczesnych grach wideo - zdarza się, że gra lub jej fragment tworzą narrację, która odnosi się do ważnej prywatnej historii jednego z jej autorów (a czasem kilku czy nawet wszystkich). I choć podobną tezę można przecież postawić w stosunku do wielu innych typów tekstów kultury, takich jak literatura, komiks czy film, to jednak trzeba podkreślić, że dopiero w ostatnich latach podobny zabieg zaczął się mieścić w normie gier komercyjnych.

\section{KONKLUZJE}

Analiza Bury me, my Love, A Normal Lost Phone oraz Wanderlust: Travel Stories pozwoliła, jak sądzę, naświetlić różne, choć z całą pewnością nie wszystkie przejawy tendencji intymistycznych we współczesnych grach wideo. Należy przy tym podkreślić, że omówione tytuły nie są jedynymi reprezentantami tego trendu, można ich wskazać więcej, pojedyncze gry tego 
rodzaju pojawiały się także wcześniej. Jednakże nasilenie się tego procesu oraz pojawianie się wyrazistych przykładów, takich jak wyżej wymienione, pozwala na sformułowanie kilku kluczowych spostrzeżeń.

1. Tym, co w perspektywie intymistycznej łączy wszystkie trzy omawiane gry, jest m.in. bardzo silne wykorzystanie żywiołu tekstu jako podstawowego materiału semiotycznego, w którym realizuje się gra. Jest to jednocześnie świadectwem pewnego szerszego zjawiska, a mianowicie swoistego $\mathrm{z}$ w rot u $\mathrm{ku}$ sło w u w produkcji gier wideo. Fakt ten - choć raczej nie jest warunkiem koniecznym ${ }^{20}$ - sprzyja wprowadzaniu wymiaru intymistycznego do dzieła. Nie powinno to zaskakiwać, skoro słowo jest szczególnie predystynowane do mówienia o przeżyciach wewnętrznych, psychicznych, duchowych ${ }^{21}$, a zgodnie z klasycznymi rozpoznaniami tartusko-moskiewskiej szkoły semiotycznej język naturalny leży u podstaw wszystkich wtórnych systemów modelujących ${ }^{22}$.

2. Dwie z trzech omawianych gier wykorzystują strategię polegającą na remediacji smartfona oraz - szerzej - współczesnej medialności cyfrowej. W obydwu przypadkach twórcy zaprojektowali nowy interfejs

20 Dowodu na to, że opieranie rozgrywki na tekście nie jest koniecznością, dostarcza np. Florence (Mountains, 2018), gdzie tekst jest zredukowany do absolutnego minimum i poza bardzo nielicznymi liniami dialogowymi występuje właściwie wyłącznie w krótkich tytułach rozdziałów sugerujących znaczenie następujących scen. Jednocześnie Florence można uznać za reprezentację nurtu intymistycznego przez wzgląd na główny temat, jakim jest rozwój relacji intymnej pary bohaterów oraz spotykające ich w związku z tym trudności.

${ }^{21}$ „Większość wzorców kulturowych (np. mit, magia, religia, nauka, system prawny, system etyczny) ma językowy charakter, są one wyrażane, przechowywane, utrwalane i przekazywane za pośrednictwem języka. [...] Znaczenia zawarte w pozostałych (tj. pozajęzykowych) systemach semiotycznych (takich jak np. obrzędy, systemy znaków grzecznościowych itp.) są interpretowane za pomocą języka, są sprowadzane do językowej wykładni świata. Język w świecie wzorców kulturowych pełni więc podwójną rolę: jedne wzorce tworzy, wyraża i przechowuje, a w stosunku do innych (pozajęzykowych) jest narzędziem interpretacji”. Zob. R. Kwaśnica, Rzeczywistość jako byt sensu. Teza o językowym tworzeniu rzeczywistości, „Język a Kultura” 1991, nr 1, s. 41.

22 Zob. chociażby: J. Łotman, O znaczeniach we wtórnych systemach modelujacych, „Pamiętnik Literacki” 1969, nr 60/1, s. 280. 
(w A Normal Lost Phone - interfejs całego systemu operacyjnego urządzenia; w Bury me, my Love - dwóch aplikacji), a nawigowanie po nim uczynili zasadniczą mechaniką rozgrywki. Oznacza to, że tendencje intymistyczne w grach wideo wymagały sięgnięcia po nowe dla tego medium formy gatunkowe ${ }^{23}$. Analizowane w niniejszym artykule przykłady ilustrują jednocześnie fakt, że gatunki te nie rodzą się ex nihilo, tylko czerpią z zastanych form medialnych, które twórczo przetwarzają.

3. Proces ten jest możliwy, ponieważ współczesna intymistyka przesunęła siębardzo wyraźnie w stronę cyfrowości, a jej podstawowym nośnikiem stały się smartfony. Ta intymistyka 2.0 jest rezultatem głębokiego zakotwiczenia i zapośredniczenia współczesnej kultury w mediach cyfrowych i jej interfejsach oraz rosnącego znaczenia smartfonów w codziennej komunikacji i konsumpcji mediów ${ }^{24}$.

4. Wspólnym mianownikiem wszystkich omówionych gier jest wykorzystywanie intymnej perspektywy do wy woływania empatii

${ }^{23}$ Victor Navarro-Remesal i Beatriz Pérez Zapata określają ten gatunek jako „inspirowane rzeczywistością gry interfejsowe" (Reality-Inspired Interface Games). Zob. V. Navarro-Remesal, B. Pérez Zapata, First-person Refugee Games: Ludonarrative Strategies for Playing the Stories of Refugees and Asylum Seekers, [w:] International Conference on Videogame Sciences and Arts, eds. N. Zagalo, A.I. Veloso, L. Costa, Ó. Mealha, Cham 2019, s. 11.

${ }^{24}$ O znaczeniu smartfonów w życiu społecznym zob. np. N. Juchniewicz, Smartfon jako interfejs życia społecznego. Raport $z$ badania, Warszawa 2015. Tekst dostępny online: https://www.delab.uw.edu.pl/wp-content/uploads/2020/07/Raport-z-badania_ smartfony_Juchniewicz.pdf [dostęp 30.03.2021]. Co ciekawe, badacze zwracają uwagę na to, jak praktyki korzystania ze smartfonów - np. nagrywania nimi filmów - wiążą się z szeroką przemianą mediów i wytwarzaniem w ich obrębie nowych standardów. Zob. G. Menotti, Discourses Around Vertical Videos: An Archaelogy of „Wrong” Aspect Ratios, „ARS” 2019, No. 35; na ten temat zob. także: M. Giżycki, Smartfon - tryumf Eisensteina, „Kwartalnik Filmowy” 2020, nr 112. Ten szeroki wpływ smartfonów nie ogranicza się zresztą do dzieł kulturalnych, lecz dotyczy niemal każdego obszaru działalności człowieka; zob. np. A. Zalewska-Bochenko, Wpływ nowoczesnych technologii na rozwój ustug bankowych, „Prace Naukowe Uniwersytetu Ekonomicznego we Wrocławiu” 2017, nr 488. 
- zrozumienia bohatera opowieści, przyjęcia na chwilę cudzej perspektywy, zbliżenia się do Obcego czy wręcz Innego. W tym sensie gry intymistyczne nabierają cech wspólnych z niektórymi grami zaangażowanymi (ang. serious games), dla których typowe jest to, że podporządkowują funkcję ludyczną innym celom (np. dziennikarskiemu czy reportażowemu opisowi rzeczywistości w przypadku gier publicystycznych). To pokrewieństwo nie powinno prowadzić jednak do wniosku o identyczności. Wszystkie trzy zanalizowane gry pozostają przede wszystkim produktami komercyjnymi, które rządzą się prawami rynku ${ }^{25}$ - i w tym sensie wydaje się ciekawe, że temat empatii jest podejmowany przez twórców i znajduje zainteresowanie. Świadczy to, jak sądzę, z jednej strony o dojrzewaniu potrzeb samych graczy $^{26}$, a z drugiej - o dojrzewaniu medium, które staje się coraz skuteczniejszym i przede wszystkim coraz bardziej wszechstronnym narzędziem do opowiadania o współczesnym świecie.

\section{Bibliografia}

Espen Aarseth, Cybertekst. Spojrzenia na literaturę ergodyczna, tłum. D. Sikora i in., Korporacja Ha!art, Kraków-Bydgoszcz 2014.

Ian Bogost, Ferrari Simon, Schweizer Bobby, Newsgames: Journalism at Play, The MIT Press, Cambridge, MA-London 2012.

Joseph Campbell, Bohater o tysiącu twarzy, tłum. A. Jankowski, Zakład Wydawniczy Nomos, Kraków 2013.

Patryk Chłopek, Intymistyka 2.0. Wpływ postępujacej dygitalizacji na badania nad współczesna prywatnością, „Sztuka Edycji” 2019, nr 2.

Damien Djaouti, Alvarez Julian, Jessel Jean-Pierre, Rampnoux Olivier, Origins of Serious Games, [w:] Serious Games and Edutainment Applications, eds. M. Ma,

A. Oikonomou, L. Jain, Springer, London 2011.

Marcin Giżycki, Smartfon - tryumf Eisensteina, „Kwartalnik Filmowy” 2020, nr 112. Darshana Jayemanne, Chronotypology: A Comparative Method for Analyzing Game Time, „Games and Culture” 2020, No. 7.

${ }^{25} \mathrm{~W}$ wypadku gier zaangażowanych zysk twórców ma zwykle wymiar głównie niematerialny, polega na poczuciu wpływu na rzeczywistość, rozwiązywaniu (lub chociaż naświetlaniu) określonego problemu społecznego.

${ }^{26}$ Notabene koresponduje to m.in. z założeniami postulowanego przez Ganszyńca nurtu Slow Games. Zob. A. Ganszyniec, op. cit. 
Natalia Juchniewicz, Smartfon jako interfejs życia społecznego. Raport z badania, DELab UW, Warszawa 2015.

Robert Kwaśnica, Rzeczywistość jako byt sensu. Teza o językowym tworzeniu rzeczywistości, „Język a Kultura” 1991, nr 1.

Jurij Łotman, O znaczeniach we wtórnych systemach modelujących, „Pamiętnik Literacki"1969, nr 60/1.

Robyn McMillan, Darshana Jayemanne, Iain Donald, Reality Inspired Games: Expanding the Lens of Games' Claims to Authenticity, [w:] DiGRA '20 - Proceedings of the 2020 DiGRA International Conference: Play Everywhere, DiGRA, b.m.w. 2020.

Gabriel Menotti, Discourses Around Vertical Videos: An Archaelogy of „Wrong” Aspect Ratios, „ARS” 2019, No. 35.

Victor Navarro-Remesal, Beatriz Pérez Zapata, First-person Refugee Games: Ludonarrative Strategies for Playing the Stories of Refugees and Asylum Seekers, [w:] International Conference on Videogame Sciences and Arts, eds.N. Zagalo, A.I. Veloso, L. Costa, Ó. Mealha, Springer, Cham 2019.

Konrad Niciński, „Drogi Żuczku!...”. O odcieniach intymności w korespondencji Wierzyński-Grydzewski-Lechoń i sposobach ich edytorskiego opracowania, „Sztuka Edycji” 2019, nr 2.

Christopher Vogler, Podróż autora. Struktury mityczne dla scenarzystów i pisarzy, tłum. K. Kosińska, Wydawnictwo Wojciech Marzec, Warszawa 2010.

Elżbieta Wichrowska, Twoja śmierć: początki dziennika intymnego w Polsce na przełomie XVIII i XIX wieku, Spectrum Press, Warszawa 2012.

Agnieszka Zalewska-Bochenko, Wpływ nowoczesnych technologii na rozwój usług bankowych, „Prace Naukowe Uniwersytetu Ekonomicznego we Wrocławiu” 2017, nr 488.

\section{Źródła internetowe}

Artur Ganszyniec, In Praise of Slow Games, Gamasutra, 24.06.2019, https://www. gamasutra.com/blogs/ArturGanszyniec/20190624/345350/In_Praise_of_Slow_ Games.php.

Opis gry A Normal Lost Phone na stronie sklepu Google Play, https://play.google.com/ store/apps/details?id=com.accidentalqueens.anormallostphone\&hl=pl\&gl=US. Opis gry Bury me, my Love na stronie sklepu Google Play, https://play.google.com/store/ apps/details?id=com.plug_in_digital.emma\&hl=en_US\&gl=US.

\section{Ludografia}

Accidental Queens, A Normal Lost Phone, 2017.

Different Tales, Wanderlust: Travel Stories, 2019.

Different Tales, Werewolf: the Apocalypse - Heart of the Forest, 2020.

Infinity Ward, Call of Duty: Modern Warfare 2, 2009.

Infinity Ward, Sledgehammer Games, Call of Duty: Modern Warfare 3, 2011.

Mountains, Florence, 2018. 
Spoken Adventures, Spoken Adventures, 2018.

The Pixel Hunt, Bury me, my Love, 2017.

\section{Inne źródła}

Autoryzowana rozmowa telefoniczna z Jackiem Brzezińskim, 30.03.2021.

\section{Wykaz ilustracji}

Il. 1. Zrzut ekranu z Call of Duty: Modern Warfare 2 - scena wybuchu bomby atomowej widziana $\mathrm{z}$ kosmosu.

Il. 2. Zrzut ekranu z gry Bury me, my Love uruchomionej na smartfonie.

Il. 3. Zrzut ekranu ze smartfona, na którym w tle uruchomiona jest gra Bury me, my Love.

Il. 4. Zrzut ekranu z gry A Normal Lost Phone (w wersji PC) - widok głównego ekranu smartfona, po którym gracz nawiguje w grze.

Il. 5. Zrzut ekranu z gry A Normal Lost Phone (w wersji PC) - widok aplikacji mailowej.

Il. 6. Zrzut ekranu z gry Wanderlust: Travel Stories prezentujący ramę narracyjną opowieści - spotkanie podróżników na Wyspie Wielkanocnej.

Il. 7. Zrzut ekranu z gry Wanderlust: Travel Stories prezentujący fragment rozdziału The Essential Gap Year - moment, w którym gracz musi zadecydować o wewnętrznej motywacji bohaterki.

Il. 8. Zrzut ekranu z gry Wanderlust: Travel Stories prezentujący początek rozdziału Today is Always Gone Tomorrow.

Adnotacja: wszystkie zrzuty ekranu zostały wykonane przez autora artykułu.

\section{Interfaces of Intimacy. Intimistic Tendencies in Contemporary Video Games}

The article concentrates on a specific tendency that can be observed in some video games created in recent years. This trend is that more and more video games present an intimate perspective and focus on the individual experience of the protagonist. The author of the article approaches the phenomenon in question mainly from the interpretative and genological perspective, since video games are not a media form commonly identified with the expression of intimate, formative or identitycreating experiences.

The author starts with an analysis of the reasons why video games and intimistic texts are commonly perceived as very distant genre forms. Then he analyzes those video games that represent the intimistic tendency: Bury me, my Love (The Pixel Hunt, 2017), A Normal Lost Phone (Accidental Queens, 2017) and Wanderlust: Travel Stories (Different Tales, 2019). The analysis leads to the following conclusions: what is common for all the three discussed games is i.a. a particularly important role of the text as the basic semiotic material in which the game is realized. Even though 
this concentration on the word is not a necessary condition of intimistic poetics - it definitely helps introducing such a dimension into the work.

What is more, two of the three discussed games use the strategy of remediating a smartphone. In both cases, the creators designed new interfaces modeled on the real ones and turned navigating on the phone screen into basic game mechanics. This, in turns, means that intimistic tendencies in video games stimulate reaching for new genre forms. This process of remediation is possible mainly because modern intimacy has shifted very clearly towards the digital, and smartphones have become its basic tool. This phenomenon, which the author of the article calls intimacy 2.0 ', is a result of the fact that: (a) contemporary culture is deeply anchored in the digital and its interfaces, and (b) the importance of smartphones in everyday communication and media consumption has been growing enormously in recent years.

The final conclusion of the paper is as follows: all the discussed games use an intimate perspective to evoke empathy, which was not a typical video game design goal. This is especially interesting, given the fact, that all the analyzed games remain primarily commercial products that are driven by the laws of the market.

Key words: video games, intimacy, interface, messaging app, smartphone

Data otrzymania tekstu: 7.04.2021 r.

Data zakończenia procesu recenzyjnego: 21.05.2021 r.

Data akceptacji tekstu do druku: 28.05.2021 r. 
